\title{
Mielopatía compresiva por Mycobacterium tuberculosis en una niña de origen indígena: un caso clínico de zona endémica amazónica
}

Compressive Myelopathy caused by Mycobacterium Tuberculosis in an indigenous background child: A clinical case located within the Amazonian endemic zone

\section{Mielopatia compressiva por Mycobacterium tuberculosis em uma menina indígena: um caso clínico da área amazônica endêmica}

Diana Carolina Leguizamón-Castillo, MD.*

Eugenia Espinosa-García, MD., Esp.**

Carol Viviana Vélez-Pachón, MD.***

Mónica Cediel-Echeverry, MD., Esp.****

\section{Resumen}

Introducción. La mielopatía compresiva es ocasionada por diversidad de condiciones. Los abscesos espinales se cuentan como una de sus causas de menor incidencia, con 0.2 a 2 casos por cada 10,000 ingresos hospitalarios, según estadísticas reportadas por el Hospital General de Massachusetts. El Mycobacterium tuberculosis es el segundo patógeno más frecuentemente implicado, con $25 \%$ de los casos. Objetivo. Presentar un caso de tuberculosis espinal en edad pediátrica, que es infrecuente pero de relevancia epidemiológica. Presentación del caso. Paciente femenina de siete años de edad, procedente de área endémica amazónica, con sintomatología de compresión de médula espinal. Su historia clínica, nexos epidemiológicos y hallazgos paraclínicos y quirúrgicos llevaron al diagnóstico de tuberculosis espinal. Recibió manejo descompresivo y terapia farmacológica con tetraconjugado, con evolución favorable al momento de su egreso. Conclusiones. La tuberculosis espinal, entidad infecciosa de baja frecuencia, requiere un alto índice de sospecha y un tratamiento oportuno. Las imágenes de resonancia magnética espinal orientan el diagnóstico, confirmándose mediante el aislamiento microbiológico del bacilo. Países como Colombia, con alta endemicidad para el Mycobacterium tuberculosis y con gran proporción de su población en riesgo, deben vigilar de manera constante la tuberculosis y tener presente esta entidad dentro de los diagnósticos diferenciales a descartar. [LeguizamónCastillo DC, Espinosa-García E, Vélez-Pachón CV, CedielEcheverry M. Mielopatía compresiva por Mycobacterium

\footnotetext{
* Médica, residente de pediatría, Universidad de la Sabana, Chía, Cundinamarca, Colombia.

** Médica, neuróloga pediatra, Instituto de Ortopedia Infantil Roosevelt, Bogotá, Cundinamarca, Colombia.

*** Médica, residente de pediatría, Universidad Militar Nueva Granada, Bogotá, Cundinamarca, Colombia.

**** Médica, pediatra, Instituto de Ortopedia Infantil Roosevelt, Bogotá, Cundinamarca, Colombia.
}

Correspondencia: Diana Carolina Leguizamón-Castillo. Calle 151 No. 13A-50, Torre 3, Apto 704. Celular: +57 3114969748. E-mail: dianalegui@ gmail.com. 
tuberculosis en una niña de origen indígena: un caso clínico de zona endémica amazónica. MedUNAB. 2018;21(1):138146. doi: 10.29375/01237047.2700].

Palabras clave: Compresión de la Médula Espinal; Tuberculosis de la Columna Vertebral; Discitis; Espondilitis; Diagnóstico; Terapéutica.

\section{Abstract}

Introduction. Compressive Myelophaty is caused by multiple factors. Spinal abscesses are one of the causes with lowest occurrence rates. According to statistics provided by Massachusetts' General Hospital, these abscesses represent from 0.2 to 2 cases in 10,000 hospital admissions. Mycobacterium tuberculosis is the second pathogen associated with this disease, as it was found in $25 \%$ of related cases. Objective. To present a spinal tuberculosis case at a pediatric age, which is an infrequent medical situation but that has epidemiologic relevance. Case Presentation. A 7 year old female patient coming from the Amazonian endemic zone with symptoms of spinal cord compression. Her medical history, epidemiological links and paraclinical and surgical findings lead to a spinal tuberculosis diagnosis. She received decompression procedures and first-line anti-tuberculous drug treatment (RIPE). At the moment of hospital discharging, the patient showed positive response and evolution to these treatments. Conclusions. Spinal tuberculosis is a lowfrequency infectious entity, that requires high level of suspicion and prompt treatment. Magnetic resonance imaging (MRI) of the spine guides towards the final diagnosis, that it is confirmed by microbiological isolation of the bacillus. Countries like Colombia, that is a high-endemic zone for Mycobacterium tuberculosis and that has a high percentage of population at risk, must keep a detailed surveillance of tuberculosis and must keep in mind this disease when constructing and ruling out differential diagnoses. [Leguizamón-Castillo DC, Espinosa-García E, Vélez-Pachón CV, Cediel-Echeverry M. Compressive Myelopathy caused by Mycobacterium Tuberculosis in an indigenous background child: A clinical case located within the Amazonian endemic zone. MedUNAB. 2018;21(1):138-146. doi: 10.29375/01237047.2700].

Keywords: Spinal Cord Compression; Spinal Tuberculosis; Discitis; Spondylitis; Diagnosis; Therapeutics.

\section{Resumo}

Introdução. A mielopatia compressiva é causada por uma variedade de condições. Abcessos na medula espinhal são contados como uma das causas de menor incidência, com 0.2 a 2 casos em cada 10,000 admissões hospitalares, segundo estatísticas relatadas pelo Hospital Geral de
Massachusetts. O Mycobacterium tuberculosis é o segundo patógeno mais frequentemente envolvido, em 25\% dos casos. Objetivo. Apresentar um caso de tuberculose espinhal em idade pediátrica que é infrequente, mas de relevância epidemiológica. Apresentação de caso. Uma paciente de sete anos de idade, da área endêmica da Amazônia, com sintomatologia de compressão medular. Sua história clínica, ligações epidemiológicas e achados paraclínicos e cirúrgicos levaram ao diagnóstico de tuberculose espinhal. A paciente recebeu tratamento descompressivo e terapia medicamentosa com tetra conjugado e teve evolução favorável no momento da alta. Conclusões. A tuberculose espinhal, infecção de baixa frequência, requer um alto índice de suspeita e tratamento oportuno. As imagens da ressonância magnética espinhal orientam o diagnóstico, confirmado por meio do isolamento microbiológico do bacilo. Países como Colômbia, com alta endemicidade para o Mycobacterium tuberculosis e com uma grande proporção de população em risco, devem monitorar constantemente a tuberculose e manter essa entidade em mente nos diagnósticos diferenciais a serem descartados. [Leguizamón-Castillo DC, Espinosa-García E, VélezPachón CV, Cediel-Echeverry M. Mielopatia compressiva por Mycobacterium tuberculosis em uma menina indigena: um caso clínico da área amazônica endêmica. MedUNAB. 2018;21(1):138-146. doi: 10.29375/01237047.2700].

Palavras-chave: Compressão da Medula Espinal; Tuberculose da Coluna Vertebral; Discite; Espondilite; Diagnóstico; Terapêutica.

\section{Introducción}

Colombia es un país con alta prevalencia e incidencia de tuberculosis (TB). En 2015, se notificaron al Sistema de Vigilancia en Salud Pública 12,918 casos de todas las formas de TB en la población general; de estos, un $18.4 \%$ pertenece a formas extrapulmonares y un $4.8 \%$, a formas osteoarticulares (1). Desde el aspecto epidemiológico, las poblaciones indígenas son consideradas de alto riesgo para TB. Así sucede con la comunidad Tikuna, asentada en territorio amazónico, al sur del país, con una población cercana a los 7,879 habitantes, según el censo de 2005 (2, 3).

La población pediátrica presenta factores de riesgo, como compromiso nutricional e inmunológico, que facilitan, en poblaciones indígenas, la presentación de formas inusuales de TB, como los abscesos espinales causantes de compresión de la médula espinal. Esta patología es ocasionada por diversidad de condiciones que implican una alta morbimortalidad y es, además, potencialmente discapacitante. Su etiología es 
múltiple: puede ser infecciosa con formación de abscesos espinales, por hematomas epidurales, por tumores extradurales, por cambios degenerativos, traumas, malformaciones vasculares y siringomielia $(4,5)$. Los abscesos epidurales, poco comunes, tienen una incidencia de 0.2 a 2 casos por cada 10,000 ingresos hospitalarios, según estadísticas reportadas por el Hospital General de Massachusetts. Cursan con alta morbilidad y con una mortalidad entre el $18 \%$ y el 31\%, según algunas series estadísticas mundiales $(6,7)$. El Mycobacterium tuberculosis es el segundo patógeno más frecuentemente implicado, después del Staphylococcus aureus, con cerca de un $25 \%$ de los casos en la población general (5).

Aunque en Colombia no se dispone de datos exactos de la prevalencia de mielopatía por abscesos espinales causados por Mycobacterium tuberculosis, se debe sospechar su presencia en nuestro medio, especialmente entre población vulnerable, como niños de poblaciones indígenas y afrocolombianos, quienes en 2012 significaron el $26.7 \%$ de los casos de TB pediátrica en el país (8). Por esta razón, en el presente estudio, se describe el caso clínico de una niña indígena con mielopatía compresiva por TB, con el objetivo de analizarlo, en el contexto de un caso clínico infrecuente de relevancia epidemiológica. Al realizar una revisión sistemática de bases de datos indexadas, como Lilacs, Bireme, PubMed o Science Direct, no se encontraron, a la fecha, otros casos reportados con este diagnóstico en población pediátrica en Colombia que permitiesen comparar los hallazgos.

\section{Presentación del caso}

Paciente femenina de siete años de edad, procedente de Leticia (Amazonas), hija de madre indígena Tikuna. Remitida de institución de primer nivel de esta ciudad a institución de tercer nivel en Bogotá, para valoración por el servicio de neuropediatría. Refiere cuadro clínico de un mes de evolución de dolor de miembros inferiores, asociado a debilidad progresiva e incapacitante hasta limitar la marcha, acompañado de episodios de retención urinaria. Había presentado un episodio gripal asociado a fiebre una semana antes del comienzo de estos síntomas. Antecedentes de importancia: cierre percutáneo de ductus arterioso persistente en su primer año de vida e hipotiroidismo subclínico, con desconocimiento de antecedentes perinatales, alimentarios y vacunales; adicionalmente, convivencia de un año y medio con un primo de 18 meses de edad que padeció TB pulmonar.
La paciente ingresa con peso de $18 \mathrm{~kg}(-2.30 \mathrm{z})$, talla de $115 \mathrm{~cm}(-1.98 \mathrm{z})$, índice de masa corporal de 13.6 $(-1.54 \mathrm{z})$, clasificado como riesgo de delgadez y de retraso en la talla; con incapacidad para la marcha, signos de motoneurona superior dados por Babinski positivo bilateral e hiperreflexia (Tabla 1), paraparesia espástica de miembros inferiores, fuerza muscular $5 / 5$ en miembros superiores y $4 / 5$ en miembros inferiores, con clonus agotable bilateral; nivel sensitivo aparenta T4, con alteración del control troncular, alteración de la marcha en bípedo y esfera mental conservada.

Paraclínicos de ingreso: hemograma con conteo total de leucocitos normal, tendencia a la neutrofilia y trombocitosis, proteína $\mathrm{C}$ reactiva aumentada, función hepática y renal normales (Tabla 2). Electromiografía $\mathrm{y}$ neuroconducciones en las cuatro extremidades normales, ecocardiograma con fracción de eyección del $80 \%$, cierre percutáneo adecuado de ductus arterioso permeable sin cortocircuito residual, insuficiencia aórtica trivial central, hipertensión pulmonar leve a moderada y buena función biventricular.

Por antecedente de proceso viral previo al cuadro clínico, se sospechó en primera instancia mielitis post infecciosa. Se solicitó resonancia magnética (RM) cerebral y de columna vertebral, se realizó desparasitación con albendazol y se ordenaron bolos de metilprednisolona, los cuales fueron completados por tres días sin observarse mejoría clínica. La RM cerebral simple y contrastada fue normal; la RM de columna a la altura de C7 hasta T4 y T5 y en T6 y T7 mostró alteración de las señales en los cuerpos vertebrales, con hiperintensidades en T2 e hipointensidades en T1, acompañándose de masa pre y paravertebral hipointensa en T1 e hiperintensa en T2, con ligera pérdida de altura en los cuerpos vertebrales

Tabla 1. Caracterización de reflejos miotendinosos en la paciente. Demuestra hiperreflexia de miembros inferiores.

\begin{tabular}{lc} 
Reflejos miotendinosos & \\
\hline Localización & Respuesta \\
\hline Miembros superiores & $++/++++$ \\
\hline Rotuliano bilateral & $+++/++++$ \\
\hline Aquiliano bilateral & $++++/++++$ \\
\hline
\end{tabular}

Fuente: Elaborado por autores 
Tabla 2. Resultados de laboratorios solicitados al ingreso de la paciente.

\begin{tabular}{|c|c|c|}
\hline \multicolumn{3}{|c|}{ Resultados de laboratorios } \\
\hline Parámetro & Resultados & Valor de referencia (-2 DE) \\
\hline \multirow[t]{6}{*}{ Hemograma } & Leucocitos $\quad 10,900$ & Leucocitos $\quad 4,500-13,500$ \\
\hline & Neutrófilos $74 \%(\uparrow)$ & Neutrófilos $51 \%$ \\
\hline & Linfocitos $22 \%$ & Linfocitos $\quad 42 \%$ \\
\hline & Monocitos $1 \%$ & Monocitos $5 \%$ \\
\hline & Eosinófilos $3 \%$ & Eosinófilos $3 \%$ \\
\hline & Plaquetas: $\quad 610,000(\uparrow)$ & Plaquetas: $\quad 150,000-350,000$ \\
\hline Hemoglobina (g/dL) & 11.7 & $13.5(11.5)$ \\
\hline Hematocrito (\%) & 36.7 & $40(35)$ \\
\hline BUN (mg/dL) & 11.11 & $5-18$ \\
\hline Creatinina (mg/dL) & 0.57 & $0.3-0.7$ \\
\hline $\mathrm{TGO}(\mathrm{U} / \mathrm{L})$ & 13.95 & $13-35$ \\
\hline $\mathrm{TGP}(\mathrm{U} / \mathrm{L})$ & 13.76 & $10-35$ \\
\hline CPK (U/L) & 60 & $20-180$ \\
\hline $\mathrm{PCR}(\mathrm{mg} / \mathrm{dL})$ & $50(\uparrow)$ & $0.0-0.5$ \\
\hline
\end{tabular}

* BUN: Nitrógeno ureico en sangre, TGO: Transaminasa glutámico-oxalacética, TGP: Transaminasa glutámico pirúvica, CPK: Creatina fosfocinasa, PCR: proteína $\mathrm{C}$ reactiva.

Fuente: Elaborado por autores

T1 a T4, T6 y T7 (Figuras 1-3), hallazgos interpretados por radiología como compatibles con linfoma.

Por el antecedente de procedencia de área endémica y nexo epidemiológico con paciente con TB, se sospechó, en segundo lugar, TB espinaly se realizaron baciloscopias seriadas en jugo gástrico, que resultaron negativas. La radiografía de tórax mostró áreas hiperopacas de calcificaciones, descartándose TB pulmonar.

Dada la persistencia de déficit neurológico, cirugía de columna realizó descompresión del canal lumbar, encontrando salida de $20 \mathrm{cc}$ de pus, con destrucción del cuerpo vertebral de T7 y espacio vertebral T7-T8, con absceso prevertebral y del canal medular que rechazaba la medula espinal. Se realizó laminectomía T7 derecha, con drenaje de absceso paravertebral desde T6 hasta T8.
Con estos hallazgos creció la sospecha de enfermedad de Pott. Sin embargo, se planteó descartar brucelosis y otras condiciones infecciosas que cursaran con inmunodeficiencia, como el virus de inmunodeficiencia humana o hepatitis B, pruebas cuyos resultados fueron negativos. Se repitió set de baciloscopias en jugo gástrico, con resultado negativo. Los cultivos de secreción del área de lesión fueron inicialmente negativos. Se realizaron hemocultivos de sitio de punción periférica con incubación por siete días, también negativos. La biopsia ósea descartó malignidad.

Se confirmó criterio tuberculínico con prueba cutánea de tuberculina positiva (derivado proteico purificado de la tuberculina, PPD por sus siglas en inglés). Con este resultado se inició manejo con tetraconjugado para TB (rifampicina/isoniazida/pirazinamida/etambutol) 


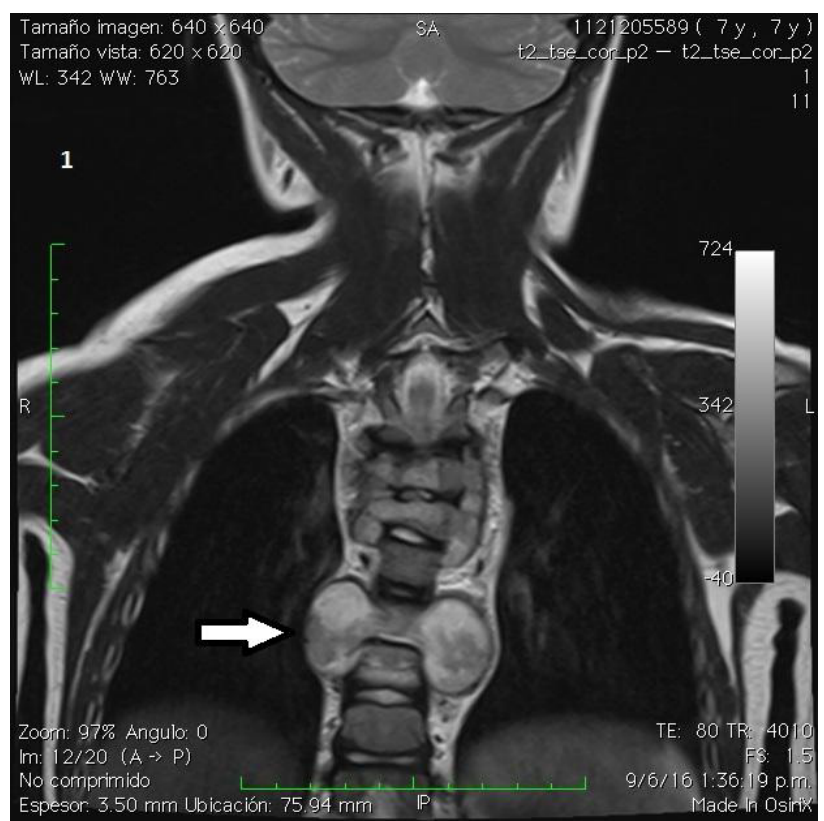

Figura 1. Resonancia magnética de columna corte coronal. La flecha blanca muestra la lesión compresiva con efecto de masa paravertebral a nivel de columna torácica. y se evidenció mejoría del compromiso motor y sensitivo, aunque persistió mayor compromiso del lado izquierdo. Simultáneamente, se remitió una muestra para estudio histopatológico de vértebra, la cual mostró enfermedad granulomatosa tipo tuberculosis. Un nuevo cultivo del tejido resecado obtuvo resultado positivo para Mycobacterium tuberculosis; el aislamiento fue remitido a la Secretaría de Salud del Distrito, para realización de pruebas de sensibilidad, que reportaron presencia de una cepa sensible. La paciente fue remitida a su sitio de origen para continuar manejo conjunto en programa de rehabilitación integral.

\section{Discusión}

Este informe presenta un caso de enfermedad de Pott, diagnosticado en una institución de tercer nivel de complejidad de la ciudad de Bogotá, enriquecedor por sus hallazgos clínicos y su raro diagnóstico en el país. La afectación de la columna vertebral por la tuberculosis se denomina espondilitis tuberculosa, también llamada enfermedad de Pott, por haber sido descrita, en Londres, por el cirujano británico Sir

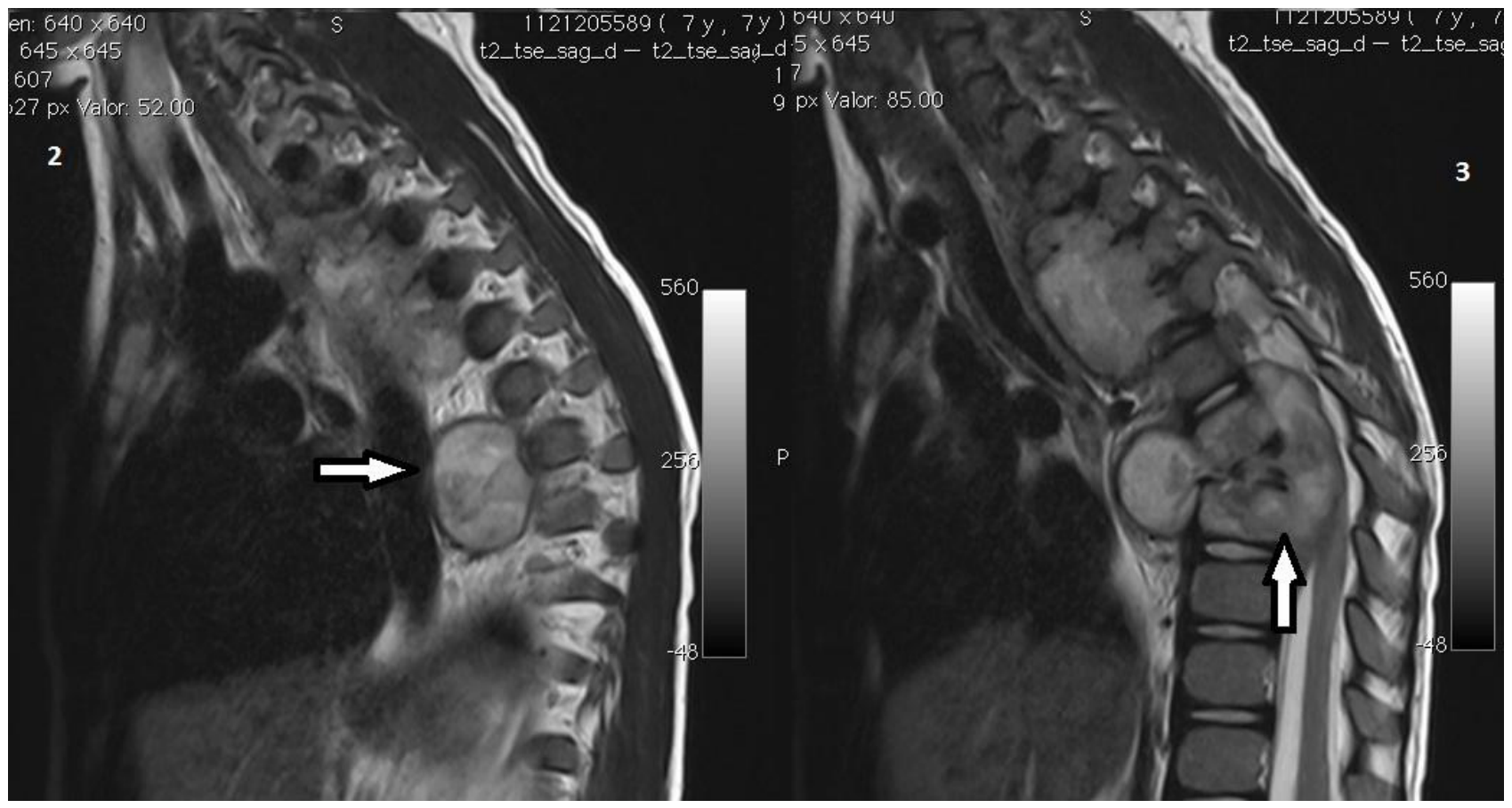

Figuras 2 y 3. Cortes sagitales de resonancia magnética de columna. La flecha blanca señala el gran tamaño del absceso, área de compromiso multivertebral y la pérdida de altura de los cuerpos vertebrales torácicos. 
Percivall Pott en el siglo XVIII (9). Es relevante por mantenerse aún como causa de morbilidad y mortalidad, pues representa entre 1 y $2 \%$ de los 400 millones de casos de tuberculosis mundial $(10,11)$. La formación de abscesos espinales representa una complicación severa, capaz de comprimir los elementos neurales y causar déficit neurológico permanente (12).

En niños, la TB afecta principalmente el sistema pulmonar y es poco frecuente la localización espinal. La presentación que compromete el hueso es más peligrosa, pues causa destrucción ósea, deformidad y paraplejía. El caso de esta paciente se presenta con cuadro de compromiso medular de predominio torácico, coincidiendo con lo reportado en la literatura, donde se ha descrito que la TB espinal afecta con más frecuencia las áreas torácicas inferiores y lumbares superiores de la columna (12). Los varones se ven afectados con mayor frecuencia en una relación 4:3 (13); como se ha mencionado, sin embargo, en este caso se trataba de una niña. Se han descrito dos formas de presentación: la espondilodiscitis (clásica) y la espondilitis sin compromiso del disco (atípica), siendo más frecuente el compromiso de múltiples vértebras contiguas (9), lo que se correlaciona con lo observado en este caso. El compromiso espinal resulta de la diseminación hematógena del Mycobacterium tuberculosis en la vasculatura del hueso esponjoso de los cuerpos vertebrales (14). El sitio de infección primaria puede ser pulmonar u otro foco extra óseo, como nódulos linfáticos, sistema gastrointestinal u otra víscera. La TB pulmonar no se detecta en el $50 \%$ de los casos de TB espinal (13), como ocurrió en el presente caso. Al llegar los bacilos al cuerpo vertebral son capturados por monocitos, células epitelioides y células de Langerhans. La reacción granulomatosa subsiguiente conduce a la expansión del cuerpo vertebral y, finalmente, al colapso (14). En el caso descrito, en el momento de la realización de las imágenes, se observaba ligera pérdida de la altura de los cuerpos vertebrales, sugiriendo un avanzado compromiso de la enfermedad.

Los síntomas y hallazgos encontrados en esta paciente sugerían presencia de mielopatía. Los síntomas que orientan el diagnóstico de estas condiciones dependerán del nivel y número de vértebras involucradas. Dentro de ellos, se encuentran: presencia de dolor lumbar, alteraciones sensoriales, síntomas motores variados, fatiga (hasta debilidad en casos severos), alteración de los reflejos miotendinosos, disfunción esfinteriana (aunque puede no estar presente, dependiendo del lugar de ubicación de la lesión), disfunción autonómica como anhidrosis o cambios cutáneos tróficos de la piel (15). Estas manifestaciones estaban presentes en la paciente, con excepción de la disfunción autonómica. Casos raros cursan con compromiso de columna cervical y se acompañan de dolor cervical y cifosis, siendo esta última una complicación tardía. El absceso puede extenderse hacia el espacio retro faríngeo y mediastino y comprometer la vía aérea con síndrome de dificultad respiratoria aguda y erosión arterial (9). Se puede observar alteración de la marcha o postura secundaria a presencia de espasmos musculares. Asimismo, podría acompañarse de síntomas sistémicos como diaforesis nocturna, fiebre o pérdida de peso (14).

Un alto índice de sospecha y una completa historia clínica son requeridos para identificar la presencia de TB espinal (16). Más del 90\% de los pacientes inmunocompetentes presentan pruebas PPD positivas, pero un resultado negativo no excluye el diagnóstico de TB de las posibilidades diagnósticas. Resultados negativos pueden encontrarse en pacientes inmunocomprometidos o que han recibido terapia inmunosupresora (corticoides), así como en quienes cursan con factores como desnutrición o edades extremas (9).

Para un diagnóstico definitivo, los bacilos deben ser cultivados y aislados del material infectado (12). Sin embargo, en ocasiones no es posible lograr un aislamiento microbiológico oportuno, debido al lento crecimiento del Mycobacterium tuberculosis. Dado que las infecciones en pediatría, generalmente, no son bacilíferas, las baciloscopias de expectoración y contenido gástrico suelen no ser útiles (17). Esto sucedió en el presente caso, que contó con dos estudios seriados de baciloscopias en jugo gástrico, de resultado negativo.

El estudio molecular de TB ha significado un avance en la detección del material genético de Mycobacterium tuberculosis de forma automatizada. Pruebas como el Xpert son capaces, incluso, de identificar resistencia a rifampicina. Con la idea de superar las debilidades de la PPD, surgieron pruebas inmunológicas como los Test de liberación de interferón gamma (IGRAs, del inglés Interferon-gamma release assays), inmunoensayos que miden la liberación de interferón gamma (IFg), producidos por linfocitos $\mathrm{T}$ sensibilizados por los antígenos de Mycobacterium tuberculosis. Según las guías europeas, serían de ayuda en el diagnóstico de TB extra pulmonar en niños (17). Esta es una prueba de alto costo, recomendada en países de baja incidencia, pero que no está disponible en todas las instituciones. Por esta causa, se sigue solicitando, en primer lugar, la PPD. 
En muchos casos en que no se logra aislar el microorganismo durante la atención inicial, el tratamiento se debe realizar teniendo en cuenta la historia clínica y examen físico, mientras se logra la confirmación definitiva (18). Así sucedió en este caso, ya que, inicialmente, en el material tomado durante el procedimiento quirúrgico, no se obtuvo aislamiento de micobacterias y las baciloscopias seriadas fueron negativas. Sin embargo, por tratarse de paciente proveniente de área endémica para $\mathrm{TB}$, con criterio epidemiológico dado por contacto con caso confirmado de TB y con factores de riesgo dados por riesgo de desnutrición y pertenencia a tribu indígena (donde la vacunación con bacilo de Calmette-Guérin o BCG es baja), junto a los hallazgos sugestivos durante el procedimiento quirúrgico y una prueba de PPD positiva, se decidió dar inicio de manera anticipada al esquema de tratamiento farmacológico anti TB. Posteriormente, la presencia de Mycobacterium tuberculosis se confirmó mediante estudio histopatológico de vertebra y un nuevo cultivo del tejido resecado.

En cuanto a imágenes diagnósticas, la radiografía simple de columna puede mostrar disminución del espacio discal o grados variables de destrucción ósea. Sin embargo, técnicas como la RM espinal han cambiado el pronóstico de los pacientes, al facilitar la identificación temprana de la lesión, aun en casos donde la sospecha diagnóstica es baja. Por ello, se considera su elección en la investigación inicial de los pacientes con mielopatía $(9,12,19)$.

A pesar de la precisión manifestada en el presente caso y de contar con varias herramientas de apoyo diagnóstico, se ha evidenciado en diferentes estudios que es común la demora en el diagnóstico, con un promedio de duración de los síntomas de seis meses. Sin embargo, el rango descrito es aún más amplio, de 0.5-37 meses (10). En este caso, se tardó aproximadamente dos meses en llegar al diagnóstico e iniciar el tratamiento, lo que se encuentra reportado dentro del promedio global.

Los diagnósticos diferenciales son múltiples, principalmente con lesiones tumorales. No obstante, tambiénotros deben ser considerados, comodesórdenes de desmielinización, deficiencia de vitamina B12, lesiones cerebrales o de médula ósea ocupando espacio, espondilitis bacteriana o micótica. Las osteomielitis vertebrales causadas por micobacterias diferentes a Mycobacterium tuberculosis y brucelosis pueden semejar la enfermedad de Pott $(9,20)$. Diferenciar la TB espinal de estas condiciones es importante, ya que el manejo de cada una es distinto y la intervención temprana minimiza complicaciones residuales (20). En el presente caso se descartó la presencia de otras comorbilidades, afianzando la posibilidad de TB espinal.

El tratamiento de esta se orienta al drenaje del absceso y manejo de la infección (21). Si la espondilitis tuberculosa se diagnostica antes de que llegue a causar compresión, algunos autores consideran administrar solo el esquema farmacológico anti TB estandarizado. Los objetivos de la cirugía son aliviar el dolor, descomprimir la médula espinal, intentar recuperar la función neurológica, reconstruir la columna para evitar deformidades posteriores y realizar desbridamiento del tejidoinfectado para evitar recurrencias dela enfermedad $(12,22)$. El compromiso neurológico de la TB espinal es benigno si se realiza descompresión urgente en etapas tempranas de la enfermedad y se utiliza abordaje anterior o posterior $(21,23)$. El pronóstico quirúrgico está asociado con: 1) compresión medular parcial; 2) corta duración de las complicaciones neurológicas; 3 ) compromiso temprano de la médula, pero inicio tardío de las complicaciones neurológicas; 4) menor edad; y 5) buen estado general (22). La paciente del caso descrito cumplía con algunos de estos criterios de buen pronóstico $\mathrm{y}$, luego de realizarse manejo quirúrgico descompresivo, presentó una evolución favorable.

La incidencia de complicaciones neurológicas se encuentra entre el 23 y el 76\% (12). La presencia de déficits neurológicos y de deformidad es la complicación más grave de la TB espinal. La paraplejía $\mathrm{y}$, algunas veces, cuadriplejía pueden presentarse hasta en el $10 \%$. Se han reportado hasta en un $10 \%$ eventos de meningomielitis (13). En este caso, la paciente mostró mejoría al egreso. Sin embargo, debe ser observada por largo tiempo para determinar presencia de futuras complicaciones residuales.

El seguimiento es importante para verificar la resolución de la infección y monitorizar posibles efectos secundarios de los medicamentos (16). A pesar de los tratamientos actuales, un $8 \%$ de las paraplejías por tuberculosis no recuperaran su funcionalidad normal (19). En pacientes en quienes se ha realizado seguimiento (de cinco a diez años luego de haber completado el tratamiento farmacológico), se ha observado un $2-5 \%$ de recurrencia o reactivación. Como causa asociada a reactivación está el inmunocompromiso causado por condiciones como diabetes, comorbilidades y vejez (19). 


\section{Conclusiones}

Casos de TB espinal, como el presentado, no son infrecuentes a nivel mundial. Países como Colombia, con alta endemicidad para el Mycobacterium tuberculosis por su gran proporción de población en riesgo, deben realizar vigilancia de TB. La presencia de síntomas neurológicos sugestivos de mielopatía obliga a descartar la posibilidad de una TB espinal, ya que un diagnóstico temprano, junto con un tratamiento adecuado, favorece un mejor pronóstico, mínimas secuelas y un bajo porcentaje de recaídas.

\section{Consideraciones éticas}

Protección de personas y animales. Los autores declaran que para esta investigación no se han realizado experimentos en seres humanos ni en animales.

Confidencialidad de los datos. Los autores declaran que han seguido los protocolos de su centro de trabajo sobre la publicación de datos de pacientes.

Derecho a la privacidad y consentimiento informado. Los autores han obtenido el consentimiento informado del acudiente de la paciente referida en el artículo. Este documento obra en poder del autor de correspondencia.

\section{Conflicto de intereses}

Los autores declaran no tener conflicto de interés.

\section{Referencias}

1. Boletín epidemiológico semanal. Semana epidemiológica 52 de 2015 [Internet]. Colombia: Instituto Nacional de Salud; 2015 [citado 8 de julio de 2016]. Recuperado a partir de: https://www.google. com.co/search?q=Colombia.+Instituto+Nacional + de + Salud.+Bolet $\%$ C3\%ADn+epidemiol\%C3\%B3gico+semanal.+Semana+epidemiol\%$\mathrm{C} 3 \% \mathrm{~B} 3$ gica $+52+\mathrm{de}+2015 \&$ oq $=$ Colombia. + Instituto + Nacional + de + Salud. + Bolet $\%$ C3\%ADn+epidemiol $\%$ C3\%B3 gico+semanal.+Semana+epidemiol $\%$ C3\%B3gica $+52+$ de $+2015 \&$ aqs $=$ chrome..69i57.686j0j7\&sourceid $=$ chrome\&ie $=$ UTF-8

2. Introducción a la Colombia Amerindia. Boletín Museo del Oro [Internet]. Colombia. Instituto Colombiano de Antropología; 1988 [citado 23 de septiembre de 2017];(20):139-41. Recuperado a partir de: https://publicaciones.banrepcultural.org/index.php/ bmo/article/view/7174/7432.
3. Tikuna, los hijos de Yoi e Ipi, y gente de tierra firme [Internet]. Colombia. Ministerio de Cultura; 2010 [citado 24 de sept 2017].

4. Arroyo HA. Mielopatías agudas no traumáticas en niños y adolescentes. Rev Neurol [Internet]. 2013 [citado 24 de septiembre de 2017];57(S1):129-38. Recuperado a partir de: https://www.neurologia. com/articulo/2013306.

5. Granados AM, García LM, Ortega CA, López A. Enfoque diagnóstico de las mielopatías. Rev Colomb Radiol. [Internet]. 2011 [citado 22 de diciembre de 2017];22(3):3231-51. Recuperado a partir de: http://www.webcir.org/revistavirtual/articulos/ diciembre11/colombia/col_espanol_a.pdf.

6. Berger JR, Sabet A. Infectious Myelopathies. Semin Neurol. [Internet]. 2002 [citado 22 de diciembre de 2017];22(2):133-41. Recuperado a partir de: https:// doi.org/10.1055/s-2002-36536.

7. DeSanto J, Ross JS. Spine Infection/Inflammation. Radiol Clin North Am. 2011;49(1):105-27. doi: 10.1016/j.rcl.2010.07.018

8. Detección oportuna de la Tuberculosis permitirá reducir la mortalidad en niños y niñas. [Internet]. Organización Panamericana de la Salud. 2013 [citado 11 de febrero de 2018]. Recuperado a partir de: http:// www.paho.org/col/index.php?option $=$ com_docman\&view $=$ download\&category_slug $=$ publicaciones-ops-oms-colombia\&alias=1403-tb-24-marzo-2013\&Itemid $=688$.

9. Manoharan SR, Leitao J, Emberton P, Quraishi NA. A large tuberculosis abscess causing spinal cord compression of the cervico-thoracic region in a young child. Eur Spine J. 2013;22(7):1459-63. doi: 10.1007/s00586-013-2729-1.

10. Ratnappuli A, Collinson S, Gaspar-García E, Richardson L, Bernard J, Macallan D. Pott's disease in twenty-first century London: spinal tuberculosis as a continuing cause of morbidity and mortality. Int $\mathrm{J}$ Tuberc Lung Dis. 2015;19(9):1125-6. doi: 10.5588/ ijtld.15.0091.

11. Ramírez E, Ochoa M, Ordoñez F. Tratamiento quirúrgico de la enfermedad de Pott por vía anterior. Columna/Columna. 2013;12(4):308-11. doi: 10.1590/S1808-18512013000400009

12. Bozzola E, Bozzola M, Magistrelli A, Calcaterra V, Larizza D, Lancella L, et al. Paediatric tubercular spinal abscess involving the dorsal, lumbar and sacral regions and causing spinal cord compression. Infez Med. [Internet]. 2013 [citado 22 de diciembre de 2017];21(3):220-3. Recuperado a partir de: 
Med Diana Carolina Leguizamón-Castillo, MD., Eugenia EspinosaGarcía, MD., Esp., Carol Viviana Vélez-Pachón, MD., Mónica CedielNAB| Echeverry, MD., Esp.

ISSN 2382.4603 Bectronico

https://www.ncbi.nlm.nih.gov/pubmed/24008856

13. Momjian R, George M. Atypical Imaging Features of Tuberculous Spondylitis: Case Report with Literature Review. J Radiol Case Rep [Internet]. 2014 [citado 6 de julio de 2016];8(11):1-14. doi: 10.3941/ jrcr.v8i11.2309

14. Kellett CG, Crocker MJ. Compressive myelopathy. Surgery. 2015;33(8):390-9. doi: 10.1016/j.mpsur.2015.05.004

15. Yusta A, Andrés del Barrio MT, Alavena M. Mielopatías. Medicine. 2011;10(77):5191-9. doi: 10.1016/ S0304-5412(11)70078-6

16. Eisen S, Honywood L, Shingadia D, Nove1 li V. Spinal tuberculosis in children. Arch Dis Child. 2012; 97(8):724-9. doi: 10.1136/archdischild-2011-301571

17. Contardo V, Cofré J, Hernández P. Mal de Pott y diagnóstico inmunológico de tuberculosis, a propósito de un caso pediátrico. Revista Chilena de Infectología. 2015; 32(1):105-10. doi: 10.4067/S071610182015000200015

18. Schmalstieg WF, Weinshenker BG. Approach to acute or subacute myelopathy. Neurology.
Vol 21(1):138-146, abril - julio 2018

2010;75(18,S1):S2-8. doi: 10.1212/WNL.0b013e$3181 \mathrm{fb} 3638$

19. Tuli SM. Historical aspects of Pott's disease (spinal tuberculosis) management. Eur Spine J. 2013; 22(S4):529-38. doi: 10.1007/s00586-012-2388-7

20. Sivalingam J, Kumar A. Spinal Tuberculosis Resembling Neoplastic Lesions on MRI. J Clin Diagn Res. 2015;9(11):TC01-TC03. doi: 10.7860/ JCDR/2015/14030.6719

21. Turgut M. Spinal tuberculosis (Pott's disease): its clinical presentation, surgical management, and outcome. A survey study on 694 patients. Neurosurg Rev. 2001;24(1):8-13. doi: 10.1007/PL00011973

22. Kumar R, Srivastava AK, Tiwari RK. Surgical management of Pott's disease of the spine in pediatric patients: A single surgeon's experience of 8 years in a tertiary care center. J Pediatr Neurosci. 2011;6(S1):S101-8. doi: 10.4103/1817-1745.85726

23. Varatharajah S, Charles YP, Buy X, Walter A, Steib JP. Update on the surgical management of Pott's disease. Orthop Traumatol Surg Res. 2014;100(2):22935. doi: 10.1016/j.otsr.2013.09.013 